\title{
Transport of Biotin in the Ileum of Suckling Rats: Characteristics and Ontogeny
}

\author{
HAMID M. SAID, ALI SHARIFIAN, AND AMIR BAGHERZADEH \\ Departments of Medicine, Physiology, and Biophysics, University of California School of Medicine, \\ Irvine, California 92717
}

\begin{abstract}
Unlike adult rats, which transport biotin preferentially in the jejunum of the small intestine, suckling rats transport biotin preferentially in the ileum. The characteristics and kinetics of the transport process of biotin in the ileum of developing suckling rats and the subsequent maturation of the process in weanling and adult rats are not known and, therefore, are examined in this study. Transport studies were performed in suckling (16-d-old), weanling (25- to 27-d-old), and adult (90-d-old) rats using the everted sac technique. Transport of biotin in the ileum of suckling rats was significantly higher $(p<0.01)$ than that in weanling rats, and transport in weanling rats was in turn significantly higher $(p<0.01)$ than that in adult rats. In all age groups examined, transport of biotin was found to be $\mathrm{Na}^{+}$-dependent and saturable as a function of concentration within the physiologic range $(<10 \mu \mathrm{M})$, but linear at high concentrations. However, the $V_{\max }$ of the carrier-mediated transport system of biotin showed progressive decrease with maturation $(3290 \pm 363,829 \pm 47$, and $463 \pm 19 \mathrm{pmol} / \mathrm{g}$ tissue wet wt/15 min in suckling, weanling, and adult rats, respectively), whereas no significant changes were observed in the apparent $\mathrm{Km}(2.8 \pm 0.6$, $2.6 \pm 0.4$, and $3.4 \pm 0.4 \mu \mathrm{M}$ in suckling, weanling, and adult rats, respectively). These findings suggest that maturation is associated with a decrease in the number (and/ or activity) but not the affinity of the ileal biotin transport carriers. Transport of biotin by the diffusion process was also found to decrease with maturation (diffusion rates of $144,86.5$, and $40 \mathrm{pmol} / \mathrm{g}$ tissue $\mathrm{wt} / 15 \mathrm{~min}$ were found for suckling, weanling, and adult rats, respectively). Unlabeled biotin, biotin-related compounds, metabolic inhibitors, and low incubation temperature all caused significant inhibition in the transport of ${ }^{3} \mathrm{H}$-biotin in the ileum of suckling as well as weanling and adult rats. These results demonstrate that biotin transport in the ileum of suckling rats is similar to that of weanling and adult rats in being carrier-mediated and $\mathrm{Na}^{+}-$, energy- and temperature-dependent. Furthermore, the results show that developmental maturation is associated with a decrease in the number (and/or activity) of the biotin transport carriers and a decrease in the diffusion rate in the ileum. (Pediatr Res 28: 266-269, 1990)
\end{abstract}

The water-soluble vitamin biotin is essential for normal growth and development (1-3). It acts as a cofactor for four mammalian carboxylases catalyzing essential pathways in fatty acid biosynthesis, gluconeogenesis, and catabolism of several branchedchain amino acids and odd-chain fatty acids (1-3). In addition,

Received January 4, 1990; accepted April 19, 1990.

Correspondence and reprint requests: Hamid M. Said, C352, Medical Sciences Building 1, Department of Medicine, University of California School of Medicine, Irvine, CA 92717.

Supported by NIH Grant DK 39501. biotin has been implicated in the regulation of gene expression of certain membrane receptors, a function that could represent a fundamental control mechanism for cell differentiation (4).

Human beings and other higher mammals cannot synthesize biotin; therefore, they must obtain the vitamin via intestinal absorption. Previous studies from our laboratory have shown that the ileum is the site of maximum transport of biotin in suckling rat intestine (5). This situation, however, was found to change with maturation, with transport becoming similar in the jejunum and ileum in weanling rats. In adult rats, biotin transport becomes significantly higher in the jejunum than in the ileum (5-9). The characteristics and kinetics of the biotin transport process in the ileum of the developing suckling rats and the subsequent maturation of the process in weanling and adult rats are not known and, therefore, are examined in this investigation. Such a study is of significant physiologic and nutritional importance because it relates to changes in the absorption of an essential nutrient during a period of rapid growth and development. Furthermore, biotin deficiency occurs in human infants under certain conditions and, if untreated, could lead to serious clinical consequences $(1-3,10,11)$.

\section{MATERIALS AND METHODS}

Materials. $\left[8,9-{ }_{-}^{3} \mathrm{H}\right]$-biotin $(40 \mathrm{Ci} / \mathrm{nmol})$ was purchased from New England Nuclear (Boston, MA). Unlabeled biotin was obtained from Sigma Chemical Co. (St. Louis, MO). All other chemicals and reagents were of analytical quality and were obtained from commercial sources. The radiochemical purity of ${ }^{3} \mathrm{H}$-biotin used in this study was $96 \%$ as determined on precoated silica gel HPTLC plates (Merck and Co., Darmstadt, FRG) using a solvent system of benzene/methanol/acetone/anhydrous acetic acid $(70 / 20 / 5 / 5$, vol/vol) (12).

Methods. Suckling (with mothers), weanling (male), and adult (male) Sprague-Dawley rats were obtained from Harlan SpragueDawley, Inc., Indianapolis, IN. Mothers, weanling, and other adult rats were fed rat chow (Ralston-Purina Co., St. Louis, MO) and tap water ad libitum. The National Council's guidelines for the care and use of laboratory animals were followed. Transport studies were performed in suckling (16-d-old), weanling (25- to 27 -d-old), and adult (90-d-old) rats using the everted sac technique (13). Rats were killed by an overdose of ether, the abdomen was opened, and the terminal part of the small intestine was removed and washed with cold buffer (we used the distal $12 \mathrm{~cm}$, $16 \mathrm{~cm}$, and $20 \mathrm{~cm}$ of the ileum in preparing everted sacs from suckling, weanling, and adult rats, respectively). Everted sacs (4 $\mathrm{cm}$ in length) were then prepared as described by us previously $(5,6,14)$. Everted sacs were incubated individually in $5 \mathrm{~mL}$ of continuously oxygenated $\left(100 \% \mathrm{O}_{2}\right)$ modified Krebs-Ringer phosphate buffer (concentration in $\mathrm{mM}$ : $\mathrm{NaH}_{2} \mathrm{PO}_{4} 20, \mathrm{NaCl}$ $125, \mathrm{KCl} 4.93, \mathrm{MgSO}_{4} 1.23, \mathrm{CaCl}_{2} 0.85$, glutamine 5, glucose 5, pH 6.5; changes in this buffer are stated in the text) containing labeled and unlabeled biotin. The serosal compartment was filled with the same buffer used for incubation. Incubation was carried 
out for $15 \mathrm{~min}$ [biotin transport in rat intestinal everted sacs is linear for up to $30 \mathrm{~min}$ of incubation $(5,6)]$ at $37^{\circ} \mathrm{C}$ (unless otherwise stated) in a shaking water bath ( 80 oscillations/min). At the end of incubation, the sacs were removed and washed with cold buffer; the serosal medium was drained into a scintillation vial, then the tissue wet wt was determined. Ten $\mathrm{mL}$ of scintillation cocktail was then added to the serosal fluid and analyzed for radioactivity. The viability of the in vitro intestinal tissue preparation has been previously demonstrated by measuring transmembrane potential difference, $\mathrm{L}-\left[{ }^{3} \mathrm{H}\right]$-leucine $(20$ $\mu \mathrm{M})$, and $\left[5-{ }^{14} \mathrm{C}\right]$-methyltetrahydrofolate $(50 \mu \mathrm{M})$ accumulation against a concentration gradient and by histologic examination of the intestinal tissue (14).

Statistical analysis. Transport data are the result of three to 13 everted sacs from three to 13 different rats and are expressed as mean $\pm \mathrm{SEM}$ in $\mathrm{pmol} / \mathrm{g}$ tissue wet $\mathrm{wt} / 15 \mathrm{~min}$. Transport results are expressed in term of tissue wet $w t$ because this parameter has been shown to be suitable for comparing transport results from rats of different age groups (15). Transport kinetic parameters, i.e. $\mathrm{V}_{\max }$ and apparent $\mathrm{Km}$, were determined using a computerized model of the Michaelis-Menten equation as described by Wilkinson (16). Data were analyzed using $t$ test and regression analysis.

\section{RESULTS}

Biotin transport in ileum of suckling, weanling, and adult rats: effect of $\mathrm{Na}^{+}$. In this study, we examined transport of $0.1 \mu \mathrm{M}$ biotin in ileal everted sacs of suckling rats and compared the results with those of weanling and adult rats. Incubation was performed in an incubation medium containing normal $\mathrm{Na}^{+}$ concentration $(145 \mathrm{mM})$ and in an incubation medium containing low- $\mathrm{Na}^{+}$concentration $(20 \mathrm{mM}$ ) (in the latter incubation medium, $\mathrm{K}^{+}$or choline was used to replace $\mathrm{Na}^{+}$). The results (Table 1) show that biotin transport in ileal everted sacs incubated in normal $\mathrm{Na}^{+}$-containing buffer was significantly higher $(p<0.01)$ in suckling rats than in weanling rats, and transport in weanling rats was in turn significantly higher $(p<0.01)$ than in adult rats, confirming previous findings in our laboratory (5). The results in Table 1 also show that lowering the $\mathrm{Na}^{+}$concentration in the incubation medium from $145 \mathrm{mM}$ to $20 \mathrm{mM}$ is associated with a significant $(p<0.01)$ inhibition in biotin transport in the ileum of rats of all age groups, regardless of whether $\mathrm{K}^{+}$or choline was used to replace $\mathrm{Na}^{+}$in the incubation medium.

Transport of biotin as function of concentration. Transport of biotin was examined as a function of concentration $(0.1-10 \mu \mathrm{M})$ in ileal everted sacs of suckling rats and the results were compared with those of weanling and adult rats (Fig. 1). In all age groups, biotin transport was found to be saturable as a function of concentration within the physiologic range $(<10 \mu \mathrm{M})$, but was linear at higher concentrations. Transport of biotin by the linear (diffusion) process occurred at a rate (i.e. diffusion rate) of 144 ,

Table 1. Biotin transport in ileum of suckling, weanling, and adult rats: effect of $\mathrm{Na}^{+*}$

\begin{tabular}{cccc}
\hline & \multicolumn{3}{c}{ Transport (pmol/g tissue wet wt/15 min) } \\
\cline { 2 - 4 } Condition & Suckling & Weanling & Adult \\
\hline $145 \mathrm{~m} \mathrm{M} \mathrm{Na}^{+}$(control) & $85.3 \pm 4.2$ & $37.0 \pm 2.5$ & $10.6 \pm 0.6$ \\
$20 \mathrm{mM} \mathrm{Na}^{+}+125 \mathrm{mM}$ & $26.8 \pm 4.2 \dagger$ & $11.8 \pm 0.9 \dagger$ & $3.32 \pm 0.6 \dagger$ \\
choline & & & \\
$20 \mathrm{mM} \mathrm{Na}^{+}+125 \mathrm{mM}$ & $16.4 \pm 1.5 \dagger$ & $15.32 \pm 1.6 \dagger$ & $2.1 \pm 0.12 \dagger$ \\
$\mathrm{K}^{+}$ & & &
\end{tabular}

* Ileal everted sacs were incubated for $15 \mathrm{~min}$ in continuously oxygenated Krebs-Ringer buffer at $37^{\circ} \mathrm{C}$ in the presence of $0.1 \mu \mathrm{M}$ biotin. Transport values are the result of three to eight everted sacs from three to eight different rats and are expressed as mean \pm SEM.

$\dagger p<0.01$ compared with simultaneously performed controls using the $t$ test.

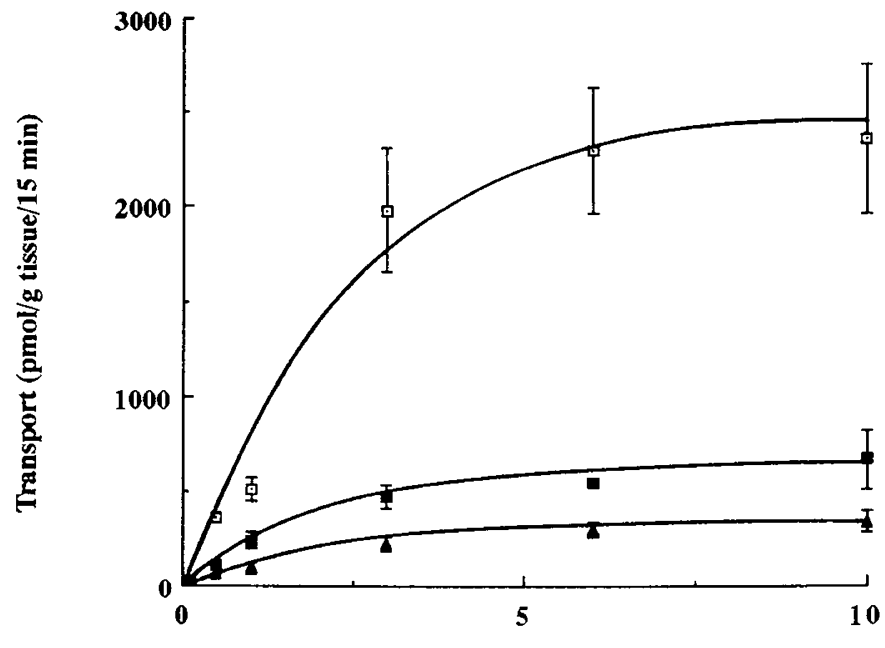

Biotin Conc. (uM)

Fig. 1. Transport of biotin as a function of concentration $(0.1-10$ $\mu \mathrm{M}$ ) in ileal everted sacs of suckling (open squares), weanling (closed squares), and adult (closed triangles) rats. Incubation was performed for $15 \mathrm{~min}$ in continuously oxygenated Krebs-Ringer buffer at $37^{\circ} \mathrm{C}$. Transport by the carrier-mediated system was calculated as described in the text. Transport values are the result of three to seven everted sacs from three to seven different rats and are expressed as mean \pm SEM.

86.5 , and $40 \mathrm{pmol} / \mathrm{g}$ tissue wet wt $/ 15 \mathrm{~min}$ in suckling, weanling, and adult rats, respectively. To determine the kinetic parameters (i.e. $\mathrm{V}_{\max }$ and the apparent $\mathrm{Km}$ ) of the carrier-mediated transport system of biotin, we first determined the amount of biotin transported by this system. This was done by eliminating the contribution of the linear (diffusion) process from the total transport of 0.1 to $10 \mu \mathrm{M}$ concentrations of biotin. Transport of biotin by the diffusion process was determined by multiplying the individual biotin concentration by the diffusion rate. The $\mathrm{V}_{\max }$ and the apparent $\mathrm{Km}$ of the carrier-mediated transport process were then determined as described in Methods. The $V_{\max }$ of the biotin transport system was found to be significantly higher $(p<0.01)$ in suckling rats than in weanling rats, and that in weanling rats was in turn significantly higher $(p<0.01)$ than that in adult rats $(3290 \pm 363,829 \pm 47$, and $463 \pm 19 \mathrm{pmol} / \mathrm{g}$ tissue wet $\mathrm{wt} / 15 \mathrm{~min}$, respectively). On the other hand, the apparent $\mathrm{Km}$ of the biotin transport system was found to be similar in rats of all age groups $(2.8 \pm 0.6,2.6 \pm 0.4$, and $3.4 \pm$ $0.4 \mu \mathrm{M}$ for suckling, weanling, and adult rats, respectively).

Effect of biotin-related compounds and unlabeled biotin on transport of ${ }^{3} \mathrm{H}$-biotin. The effect of adding to the incubation medium $50 \mu \mathrm{M}$ of the biotin structural analogue desthiobiotin and the related compound thioctic acid, and the effect of unlabeled biotin on the transport of physiologic concentration of ${ }^{3} \mathrm{H}$ biotin $(0.1 \mu \mathrm{M})$ in ileal everted sacs of suckling rats was examined in this study. The results (Table 2) showed that all compounds tested caused significant $(p<0.01)$ inhibition in the transport of ${ }^{3} \mathrm{H}$-biotin. Similarly, $50 \mu \mathrm{M}$ desthiobiotin, thioctic acid, and unlabeled biotin caused significant $(p<0.01)$ inhibition of the transport of $0.1 \mu \mathrm{M}{ }^{3} \mathrm{H}$-biotin in ileal everted sacs of weanling and adult rats (Table 2).

Effect of metabolic inhibitors and temperature on biotin transport. The effect of the metabolic inhibitors 2,4-dinitrophenol (1 $\mathrm{mM})$ and iodoacetate $(1 \mathrm{mM})$ on the transport of $0.1 \mu \mathrm{M}$ biotin in ileal everted sacs of suckling rats was examined in this study. Both metabolic inhibitors tested caused significant $(p<0.01)$ inhibition in biotin transport (Table 3). Similarly, the transport of biotin in ileal everted sacs of weanling and adult rats was significantly $(p<0.01)$ inhibited by 2,4 -dinitrophenol $(1 \mathrm{mM})$ and iodoacetate $(1 \mathrm{mM})$ (Table 3$)$.

In another study, we examined the effect of incubation temperature $\left(27^{\circ} \mathrm{C}\right.$ versus $\left.37^{\circ} \mathrm{C}\right)$ on the transport of $0.1 \mu \mathrm{M}$ biotin in 
Table 2. Effect of biotin-related compounds and unlabeled biotin on transport of physiologic concentration of ${ }^{3} \mathrm{H}$-biotin in ileal everted sacs of suckling, weanling, and adult rats*

Transport (pmol/g tissue wet wt/15 $\min$ )

\begin{tabular}{lccc}
\cline { 2 - 4 } \multicolumn{1}{c}{ Compound } & Suckling & Weanling & \multicolumn{1}{c}{ Adult } \\
\hline Control & $110.0 \pm 23.0$ & $37.0 \pm 2.5$ & $11.5 \pm 0.8$ \\
Desthiobiotin $(50 \mu \mathrm{M})$ & $33.0 \pm 7.4 \dagger$ & $8.8 \pm 1.7 \dagger$ & $3.31 \pm 0.2 \dagger$ \\
Thioctic acid $(50 \mu \mathrm{M})$ & $40.4 \pm 7.0 \dagger$ & $9.7 \pm 1.3 \dagger$ & $3.0 \pm 0.3 \dagger$ \\
Unlabeled biotin $(50 \mu \mathrm{M})$ & $31.3 \pm 2.1 \dagger$ & $10.8 \pm 0.6 \dagger$ & $3.2 \pm 0.2 \dagger$ \\
\hline
\end{tabular}

* Ileal everted sacs were incubated for $15 \mathrm{~min}$ in continuously oxygenated Krebs-Ringer buffer at $37^{\circ} \mathrm{C}$ in the presence of $0.1 \mu \mathrm{M}{ }^{3} \mathrm{H}$-biotin and $50 \mu \mathrm{M}$ of the related compound under investigation. Transport values are the result of three to 13 everted sacs from three to 13 different rats and are expressed as mean \pm SEM.

$\dagger p<0.01$ compared with simultaneously performed controls using the $t$ test.

Table 3. Effect of metabolic inhibitors and temperature on the transport of biotin in ileal everted sacs of suckling, weanling, and adult rats*

\begin{tabular}{lccc}
\hline & \multicolumn{3}{c}{ Transport $(\mathrm{pmol} / \mathrm{g}$ tissue wet wt/15 } \\
& \multicolumn{3}{c}{ min $)$} \\
\cline { 2 - 4 } \multicolumn{1}{c}{ Condition } & Suckling & Weanling & Adult \\
\hline Control $\left(37^{\circ} \mathrm{C}\right)$ & $91.1 \pm 6.4$ & $37.0 \pm 2.2$ & $11.3 \pm 0.7$ \\
$2,4-$ Dinitrophenol $(1 \mathrm{mM})$ & $15.8 \pm 2.7 \dagger$ & $13.0 \pm 1.9 \dagger$ & $3.3 \pm 0.3 \dagger$ \\
Iodoacetate $(1 \mathrm{mM})$ & $19.3 \pm 7.2 \dagger$ & $15.7 \pm 0.4 \dagger$ & $4.8 \pm 0.4 \dagger$ \\
$27^{\circ} \mathrm{C}$ & $18.8 \pm 2.6 \dagger$ & $9.5 \pm 0.8 \dagger$ & $2.2 \pm 0.1 \dagger$ \\
\hline
\end{tabular}

* Ileal everted sacs were incubated for $15 \mathrm{~min}$ in continuously oxygenated Krebs-Ringer buffer in the presence of $0.1 \mu \mathrm{M}$ biotin and the metabolic inhibitor under investigation. Transport values are the result of three to eight everted sacs from three to eight different rats and are expressed as mean $\pm \mathrm{SEM}$.

$\dagger p<0.01$ compared with simultaneously performed controls using the $t$ test.

ileal everted sacs of suckling rats by determining the $Q_{10}$ value of the transport process (i.e. the ratio of the rate of transport of biotin at $37^{\circ} \mathrm{C}$ to the rate of transport at $27^{\circ} \mathrm{C}$ ). The results were compared with those of weanling and adult rats. $\mathrm{Q}_{10}$ values of 5.6, 4.0, and 5.2 were found for biotin transport in the ileum of suckling, weanling, and adult rats, respectively.

\section{DISCUSSION}

Developmental changes in the mechanism, efficiency, and preferential site of intestinal transport of nutrients and substrates occur during the early stages of life (14, 15, 17-19). Previous studies from our laboratory (5) have shown that the ileum is the site of maximum transport of biotin in the small intestine of suckling rats, a situation that changes with maturation. First, biotin intestinal transport becomes similar in the jejunum and the ileum during the weanling period; then, the transport becomes significantly higher in the jejunum than the ileum in adulthood (5-9). The characteristics and kinetics of the biotin transport process in the developing ileum of suckling rats and the subsequent maturation of the process in weanling and adult rats are not known and, therefore, were examined in this investigation. Biotin ileal transport was found to be significantly higher in suckling than in weanling rats, and was in turn significantly higher in weanling than in adult rats. Transport of biotin in the ileum of suckling rats was $\mathrm{Na}^{+}$-dependent, inasmuch as lowering the $\mathrm{Na}^{+}$concentration in the incubation medium from 145 to $20 \mathrm{mM}$ caused significant inhibition of transport of biotin regardless of the monovalent cation (choline or $\mathrm{K}^{+}$) used to replace it. Similarly, transport of biotin in the ileum of weanling and adult rats was found to be $\mathrm{Na}^{+}$-dependent. The exact nature of the $\mathrm{Na}^{+}$effect on biotin transport in rat ileum is not clear, but could not indicate the existence of a biotin: $\mathrm{Na}^{+}$cotransport mechanism, as has been suggested by us, in jejunal brush border membrane vesicles of rats and humans $(7,20)$.

To determine the kinetic parameters of the biotin transport process in the ileum of the developing suckling rats and delineate the mechanism responsible for the enhancement of biotin transport during the early stages of life, we examined biotin transport as a function of concentration in ileal everted sacs of suckling rats and compared the results with those of weanling and adult rats. In all age groups examined, biotin transport was found to be saturable at low physiologic concentrations $(<10 \mu \mathrm{M})$ but linear at high concentrations. These findings indicate that biotin transport at low concentrations involves a carrier-mediated process, whereas it is nonmediated (i.e. occurs by simple diffusion) at high concentrations. The ability of $50 \mu \mathrm{M}$ of the structural analogue desthiobiotin and the related compound thioctic acid, as well as unlabeled biotin, to significantly inhibit the transport of $0.1 \mu \mathrm{M}{ }^{3} \mathrm{H}$-biotin in the ileum of rats of the different age groups further confirm the existence of a carrier-mediated system for the vitamin transport in rat ileum. Despite the above described similarities in biotin transport in the ileum of rats of different ages, some distinct maturational changes in the transport kinetic parameters were observed with maturation. Although no significant changes were found in the apparent $\mathrm{Km}$ of the biotin transport carrier (apparent $\mathrm{Km}$ of $2.8 \pm 0.6,2.6 \pm$ 0.4 , and $3.4 \pm 0.4 \mu \mathrm{M}$ for suckling, weanling, and adult rats, respectively), significant and progressive decrease in the $V_{\max }$ of the biotin transport process was observed with maturation $\left(\mathrm{V}_{\max }\right.$ of $3290 \pm 363,829 \pm 47$, and $463 \pm 19 \mathrm{pmol} / \mathrm{g}$ tissue wet wt/ $15 \mathrm{~min}$ for suckling, weanling, and adult rats, respectively). These findings suggest that, although developmental maturation has no effect on the affinity of the biotin transport carrier, it is associated with a sharp decrease in the number (and/or activity) of the functional biotin transport carriers. Biotin transport by the diffusion process was also found to decrease with maturation (diffusion rates of $144,86.5$, and $40 \mathrm{pmol} / \mathrm{g}$ tissue wet wt/15 min in suckling, weanling, and adult rats, respectively). The physiologic factors that cause these developmental changes in biotin transport are not clear at this stage but could include, among other things, hormonal $(21,22)$ and physiochemical changes in the enterocyte membranes $(23,24)$. The physiologic importance of a higher level of biotin transport in the ileum than in the jejunum of suckling rats is also not clear. It could, however, be [as suggested before with other nutrients $(25,26)]$ designed to ensure efficient absorption of luminal biotin at a stage when the proximal part of the small intestine is more involved with absorption of larger amounts of colostral proteins (17).

Biotin transport in the ileum of suckling rats was also found to be similar to that of weanling and adult rats in being energyand temperature-dependent. These conclusions are based on the observations that biotin transport in the ileum of rats of different age groups was significantly inhibited by the addition of the metabolic blockers dinitrophenol and iodoacetate to incubation medium and by lowering the incubation temperature from $37^{\circ} \mathrm{C}$ to $27^{\circ} \mathrm{C}$

The characteristics of biotin transport in rat ileum of saturation, inhibition by biotin-related compounds, and $\mathrm{Na}^{+}$, energy-, and temperature-dependency are all similar to those observed for biotin transport in rat jejunum (5-7). Similarly, the decrease with maturation in the rate of biotin transport by the diffusion process is similar to that observed in the jejunum (5). However, in the ileum, developmental maturation was found to be associated with a decrease in the $\mathrm{V}_{\max }$ of the biotin transport process with no changes in the apparent $\mathrm{Km}$ of the carrier system (5). This is in contrast to the progressive increase with maturation in both the $\mathrm{V}_{\max }$ and the apparent $\mathrm{Km}$ of the biotin transport process in the jejunum. These findings indicate that maturation is associated with a redistribution of the number (and/or activity) of the biotin transport carriers along the length of the small 
intestine and a decrease in the affinity of the biotin transport carrier in the jejunum.

In summary, our study demonstrates that biotin transport in the ileum of suckling rats is similar to that of weanling and adult rats in being carrier-mediated and $\mathrm{Na}^{+}-$, energy-, and temperature-dependent. Moreover, developmental maturation is associated with a decrease in the number (and/or activity) of the transport carriers and in the diffusion rate of biotin transport in the ileum.

\section{REFERENCES}

1. Bonjour JP 1984 Biotin. In: Machlin LJ (ed) Handbook of Vitamins; Nutritional, Biochemical, and Clinical Aspects. Marcel Dekker, New York, pp $403-435$

2. Sweetman L, Nyhan WL 1986 Inheritable biotin-treatable disorders and associated phenomena. Annu Rev Nutr 6:314-343

3. Dakshinamuri K, Chauhan J 1988 Regulation of biotin enzymes. Annu Rev Nutr 8:211-233

4. Collins JC, Paietta E, Green R, Morell AG, Stockert RJ 1988 Biotin-dependen expression of the asialoglycoprotein receptor in $\mathrm{HepG}_{2}$. J Biol Chem 263:11280-11283

5. Said HM, Redha R 1988 Ontogenesis of the intestinal transport of biotin in the rat. Gastroenterology 94:68-72

6. Said HM, Redha R 1987 A carrier-mediated system for transport of biotin in rat intestine in vitro. Am J Physiol 252:G52-G55

7. Said HM, Redha R 1988 Biotin transport in brush border membrane vesicles of rat small intestine. Biochim Biophys Acta 945:195-201

8. Bowman BB, Selhub J, Rosenberg IH 1986 Intestinal absorption of biotin in the rat. J Nutr 116:1266-1271

9. Bowman BB, Rosenberg $\mathrm{IH} 1987$ Biotin absorption by distal rat intestine. J Nutr 117:2121-2126

10. Nisenson A 1931 Seborrhoeic dermatitis of infants and Leiner's disease: a biotin deficiency. Internat J Vit Nutr Res 54:223-231

11. Messaritakis J, Katlamis C, Karabula C, Matsaniotis N 1975 Generalized seborrhoeic dermatitis: clinical and therapeutic data of 25 patients. Arch Dis Child 50:871-874

12. Bonjour JP, Bauich J, Suormala T, Baumgatner ER 1984 Detection of biocytin in urine of children with congenital biotinidase deficiency. Int J Vitam Nut Res 54: 223-231

13. Wilson TH, Wiesman G 1954 The use of everted sacs of small intestine for the study of the transfer of substances from the mucosal to the serosal surface. J Physiol (Lond) 123:116-125

14. Said HM, Ghishan FK, Murrell J 1985 Ontogenesis of the intestinal transport of 5-methyltetrahydrofolate in the rat. Am J Physiol 249:G567-G571

15. Younoszai MK, Komnick K 1982 Maturation of the small intestine: absorption of $L$-valine in rats. Pediatr Res 16:756-760

16. Wilkinson GN 1961 Statistical estimation in enzyme kinetics. Biochem J 80:324-332

17. Hennings ST 1987 Functional development of the gastrointestinal tract. In Johnson LR (ed) Physiology of the Gastrointestinal Tract, Raven Press, New York, pp. 282-300

18. Barnard J, Ghishan FK, Wilson FA 1985 Ontogenesis of taurocholate transport by rat ileal brush border membrane vesicles. J Clin Invest 75:869-873

19. Said HM, Ong D, Redha R 1988 Intestinal uptake of retinol in suckling rats: characteristics and ontogeny. Pediatr Res 24:481-485

20. Said HM, Redha R, Nylander W 1987 A carrier-mediated, $\mathrm{Na}^{+}$gradientdependent transport for biotin in human intestinal brush border membrane vesicles. Am J Physiol 253:G631-G633

21. Little JM, Lester R 1980 Ontogenesis of intestinal bile salt absorption in the rat. Am J Physiol 239:G319-G323

22. Forstuer $G$, Garland $G 1976$ Influence of hydrocortisone in the synthesis and turn over of microvillus membrane glycoproteins in suckling rat intestine. Can J Biochem 54:224-230

23. Schwarz SM, Hostether B, Ling S, Mone M, Watkins JB 1985 Intestinal membrane lipid composition and fluidity during development in the rat. Am J Physiol 248:G200-G207

24. Meddings JB, Theisen $S 1989$ Development of rat jejunum: lipid permeability, physical properties and chemical composition. Am J Physiol 256:G931G940

25. Sepulveda FV, Smith MW 1979 Different mechanisms for neutral amino acid uptake by new-born pig colon. J Physiol (Lond) 286:479-490

26. Henriques C, Smith MV 1974 Sodium transport by the small intestine of newborn and suckling pigs. J Physiol (Lond) 243:211-224 